\title{
Article
}

\section{Relay Feedback Identification for Actuators with Hysteresis}

Yu-Chang Cheng, and Cheng-Ching Yu

Ind. Eng. Chem. Res., 2000, 39 (11), 4239-4249 • DOI: 10.1021/ie000008h

Downloaded from http://pubs.acs.org on November 28, 2008

\section{More About This Article}

Additional resources and features associated with this article are available within the HTML version:

- $\quad$ Supporting Information

- Access to high resolution figures

- $\quad$ Links to articles and content related to this article

- $\quad$ Copyright permission to reproduce figures and/or text from this article

\section{View the Full Text HTML}

\section{ACS Publications}




\title{
Relay Feedback Identification for Actuators with Hysteresis
}

\author{
Yu-Chang Cheng and Cheng-Ching Yu* \\ Department of Chemical Engineering, National Taiwan University of Science and Technology, \\ 43, Keelung Rd., Sec. 4, Taipei 106-07, Taiwan
}

\begin{abstract}
In this work the relay feedback identification is extended to handle imperfect actuators. In particular, the effects of actuator with hysteresis on relay feedback are explored. Comparisons are made between the ideal and saturation relays. Results show that the ramp behavior of the saturation relay can alleviate the overestimate in the ultimate gain. However, it still results in oscillatory closed-loop responses as the width of hysteresis increases. Two approaches are proposed to overcome the inaccuracy in the estimate of ultimate properties. If the width of hysteresis is known a priori (e.g., from estimation, bump test etc.), the shape of the relays can be modified to regain the accuracy in the estimate of ultimate properties. Another approach is to identify the width of the hysteresis and ultimate properties simultaneously. This is a simple modification of existing relay feedback tests. The method is tested on linear systems with and without measurement noise as well as nonlinear recycle plant. Simulation results show that very good estimates of ultimate properties can be obtained using the proposed method. It provides better reliability for the autotuning under imperfect actuators.
\end{abstract}

\section{Introduction}

Several recent surveys indicate that PID control performance is not as good as one might think ${ }^{3,4}$ and control valves contributed significantly to the poor performance. ${ }^{10}$ Due to reducing cost, many control valves are not properly installed (e.g., with positioner or flow controller) or maintained. This is unfortunate since the true value of the final control element in terms of quality, yield, and productivity usually is not recognized. Therefore, in process industries, we encounter many imperfect valves (e.g., valves with a dead-zone, stick/slip, hysteresis)

On the other hand, the past decade has seen significant progress in the autotuning of PID controllers. Most of approaches are the variation of the Åström-Hägglund relay feedback tests. ${ }^{1}$ First, a continuous cycling of the controlled variable is generated from a relay feedback experiment and the important process information, ultimate gain $\left(\mathrm{K}_{\mathrm{u}}\right)$ and ultimate frequency $\left(\omega_{\mathrm{u}}\right)$, can be extracted directly from the experiment. ${ }^{5,9,11,16} \mathrm{~A}$ controller can be designed according to $\mathrm{K}_{\mathrm{u}}$ and $\omega_{\mathrm{u}}$ (e.g., ZieglerNichols types of methods. ${ }^{11,14,16,18,19}$ Applications of relay feedback based autotuners are shown throughout process industries.

Recent years have seen renewed interest in the study of linear systems in the presence of imperfect actuators. Adaptive schemes and fuzzy control are proposed for dead-zone and/or hysteresis compensation.7,8,13 Mechanical motion control is a typical area of application. Less attention is paid to pneumatic actuators. 6,10 The problem of imperfect actuators can become quite severe when autotuners are employed to find controller parameters. The standard autotuning procedure can lead to erroneous results, and performance of the control loops degrades drastically. ${ }^{15} \mathrm{~F}$ or example, an ideal relay feedback test tends to overestimate the ultimate gain

* To whom all correspondence should be addressed. Email: ccyu@ch.ntust.edu.tw. Fax: +886-2-2737-6644. Tel: +886-2-2737-6620.
(A)

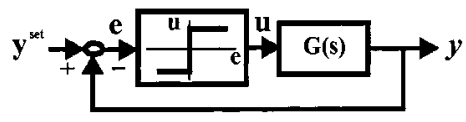

(B)

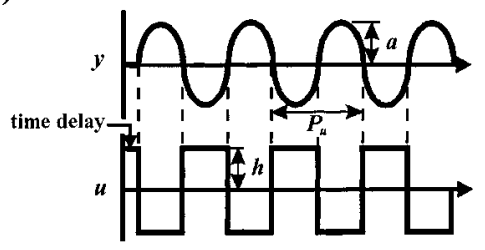

Figure 1. (A) Block diagram for a relay feedback system and (B) relay feedback test for a system with positive steady-state gain.

for valves with hysteresis and this, subsequently, leads to oscillatory or unstable closed-loop responses.2,10

The objective of this work is to study quantitatively the estimation errors (in $\mathrm{K}_{\mathrm{u}}$ and $\omega_{\mathrm{u}}$ ) for valves with hysteresis under relay feedback. Comparisons are also made between ideal relay and the saturation (ramptype) relay. ${ }^{18}$ Next, an approach for simultaneous identification of ultimate properties and width of hysteresis is proposed. The proposed relay feedback tests successfully identify the $\mathrm{K}_{\mathrm{u}}$ and $\omega_{\mathrm{u}}$ as well as possible hysteresis. Simulation results show that better control performance can be achieved with identified process information.

\section{Problems}

Åström and Hägglund ${ }^{1}$ suggest the relay feedback test to generate sustained oscillation as an alternative to the conventional continuous cycling technique. It is very effective in determining the ultimate gain and ultimate frequency.

Consider a relay feedback system where $\mathrm{G}(\mathrm{s})$ is the process transfer function, $y$ is the controlled output, $y^{\text {set }}$ is the set point and $u$ is the manipulated input. An ideal (on-off) relay is placed in the feedback loop. Figure 1 illustrates how the relay feedback system works. A relay of magnitude $h$ is inserted in the feedback loop. I nitially, 
(A)

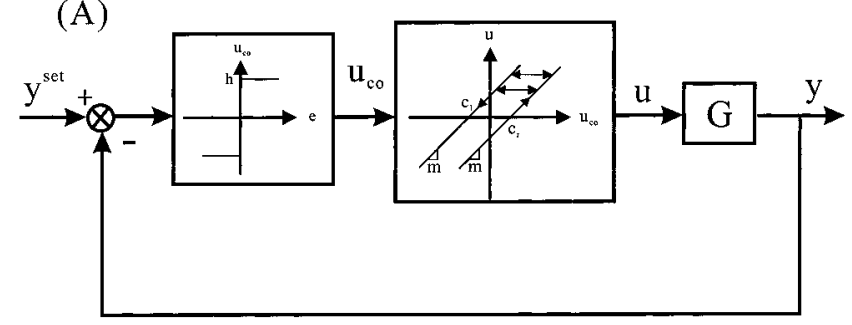

(B)

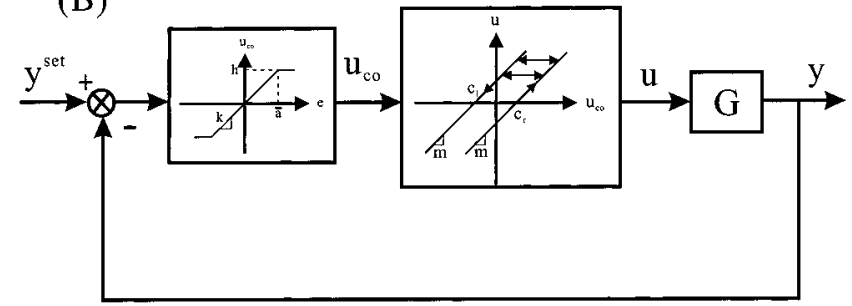

Figure 2. Actuator with hysteresis under $(A)$ ideal relay feedback and (B) saturation relay feedback.

the input $u$ is increased by $h$. As the output y starts to increase (after a time delay D), the relay switches to the opposite position, $u=-h$. Since the phase lag is $-\pi$, a limit cycle with a period $P_{u}$ results. The period of the limit cycle is the ultimate period. Therefore, the ultimate properties from this relay feedback experiment are:

$$
\begin{array}{r}
\omega_{\mathrm{u}}=\frac{2 \pi}{\mathrm{P}_{\mathrm{u}}} \\
\mathrm{K}_{\mathrm{u}}=\frac{4 \mathrm{~h}}{\pi \mathrm{a}}
\end{array}
$$

where $h$ is the height of the relay and $a$ is the amplitude of oscillation. For the saturation relay (F igure $2 \mathrm{~B}), \mathrm{K}_{\mathrm{u}}$ can be computed from ${ }^{12}$

$$
K_{u}=\frac{2 h}{\pi}\left[\left(\frac{1}{\bar{a}} \sin ^{-1} \frac{\bar{a}}{a}\right)+\left(\frac{\sqrt{a^{2}-\bar{a}^{2}}}{a^{2}}\right)\right]
$$

where $\overline{\mathrm{a}}=\mathrm{h} / \mathrm{k}$.

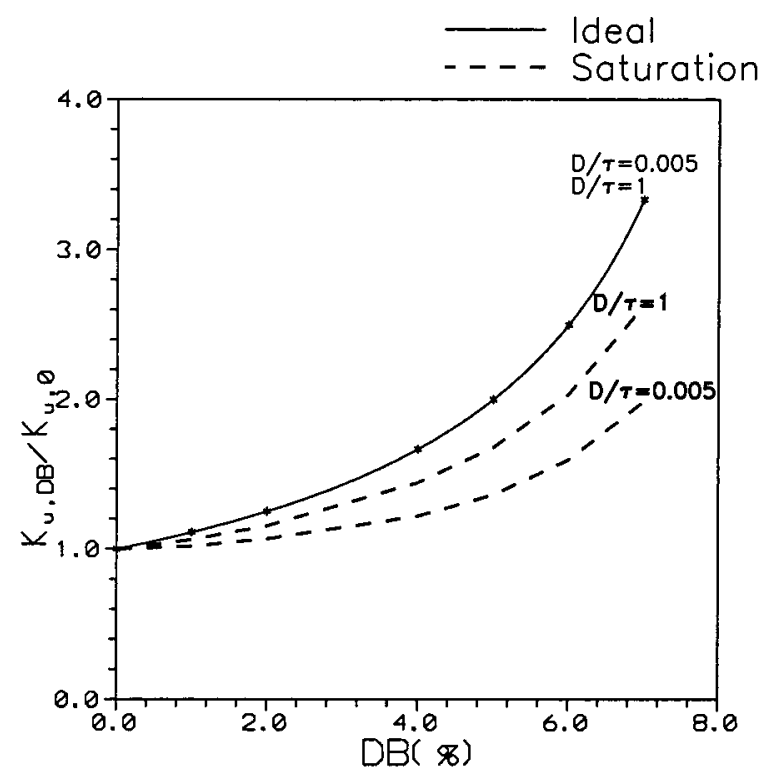

Consider an imperfect actuator in a feedback loop with the process $\mathrm{G}$ (s) and a controller K(s). An imperfect actuator is characterized by the hysteresis width and a slope as shown in Figure 2. The input and output of the hysteresis, $\mathrm{u}_{\mathrm{co}}$ and $\mathrm{u}$, are described by: ${ }^{13}$

$$
\begin{aligned}
& \mathrm{u}_{\mathrm{co}}(\mathrm{t})= \\
& \left\{\begin{array}{l}
m\left(u(t)-c_{1}\right), \quad u(t)<c_{1}+\frac{u_{c o}(t-1)}{m} \\
m\left(u(t)-c_{r}\right), \quad u(t)>c_{r}+\frac{u_{c o}(t-1)}{m} \\
u(t-1), \quad c_{1}+\frac{u_{c o}(t-1)}{m} \leq u(t) \leq c_{r}+\frac{u_{c o}(t-1)}{m}
\end{array}\right.
\end{aligned}
$$

where $t$ is the index of time, $\mathrm{u}_{\mathrm{co}}$ is the controller output, $\mathrm{u}$ is the actual position of the actuator, $\mathrm{m}$ is the slope of hysteresis, and $c_{r}$ and $c_{c}$ (negative) are constants that describe the width of the hysteresis. Here we assume $m=1$ and $\left|C_{l}\right|=\left|c_{r}\right|$. The width of the hysteresis (dead band, DB) is defined as

$$
\mathrm{DB}=\mathrm{C}_{\mathrm{r}}-\mathrm{C}_{\mathrm{l}}
$$

Let us use a typical process transfer function to illustrate the effect of actuator hysteresis on ultimate properties. This is a nth order plus time delay system.

$$
\mathrm{G}(\mathrm{s})=\frac{\mathrm{K}_{\mathrm{p}} \mathrm{e}^{-\mathrm{Ds}}}{(\tau \mathrm{s}+1)^{\mathrm{n}}}
$$

First let $\mathrm{n}=1$, a first-order system, and a time constant of $20(\tau=20)$ and steady-state gain of one $\left(K_{p}=1\right)$ are assumed. Two types of relays are considered: an ideal relay and a saturation relay (Figure 2). A relay height (h) of $5 \%$ is used in both cases. F or the saturation relay, the slope $(\mathrm{k})$ is taken as $1.4 \mathrm{~K}_{\mathrm{u}}$ to ensure a successful test ${ }^{12}$ (Figure 2B). Figure 3 shows the relative error in $\mathrm{K}_{\mathrm{u}}$ and $\mathrm{P}_{\mathrm{u}}$ as the width of hysteresis (DB) changes. As expected, the error in $\mathrm{K}_{\mathrm{u}}$ increases as DB increases for both cases. When DB reaches 5\%, the ideal relay feedback overestimates $K_{u}$ by a factor of 2 !

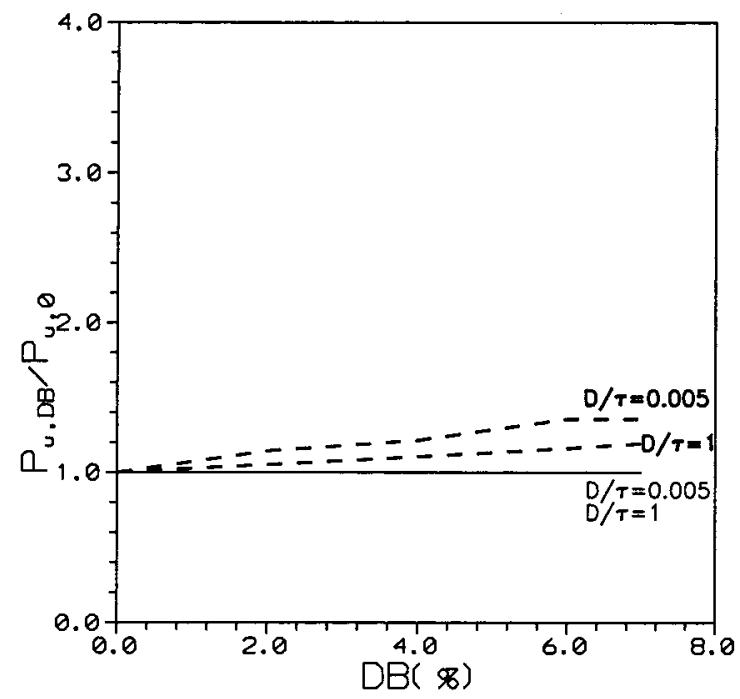

Figure 3. Effects of hysteresis width (DB) on estimation errors for ideal and saturation relays for first-order system with different $D / \tau$ ratios. 

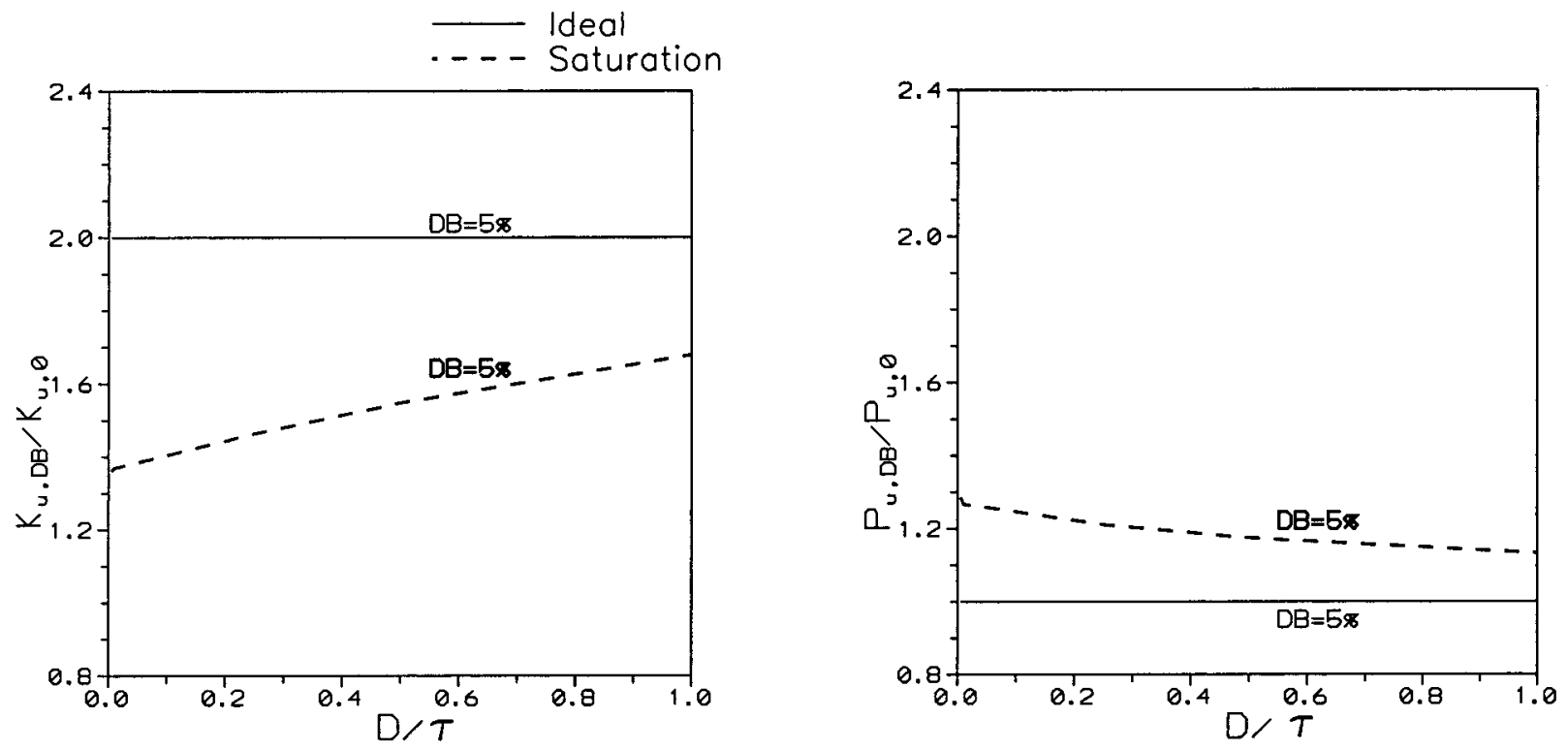

Figure 4. Effects of time delay to time constant $(D / \tau)$ ratios on estimation errors for ideal and saturation relays for first-order system with $\mathrm{DB}=5 \%$.
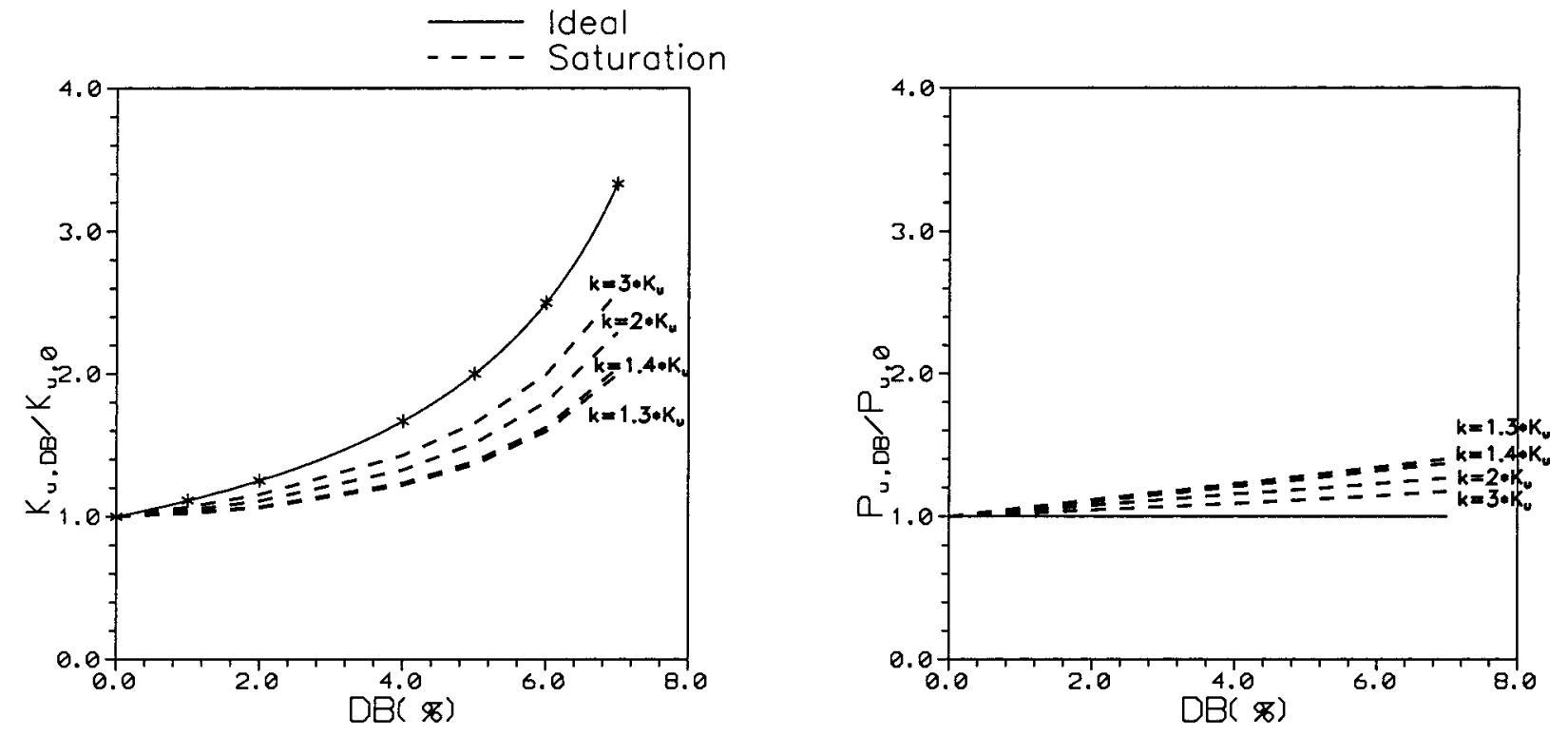

Figure 5. Effects of hysteresis width (DB) on estimation errors for first-order system with the saturation relays using different slopes (k) with $\mathrm{D} / \tau=0.005$.

That means a relay-feedback autotuner with ZieglerNichols tuning can produce an unstable closed-loop system, if DB is greater than $5 \%$. The saturation relay shows some improvement on the estimation error for $\mathrm{K}_{\mathrm{u}}$. F or the ultimate period, the ideal relay produces a correct estimate, and the saturation relay, on the other hand, shows a maximum error of $35.71 \%$ (Figure 3) for a DB of $7 \%$ (Figure 3). Notice that an overestimate in $\mathrm{P}_{\mathrm{u}}$ tends to give a more sluggish response, since we have a larger reset time $\left(\tau_{1}\right)$. Figure 4 shows how the estimation errors vary with the time delay $(\mathrm{D} / \tau)$. F or the ideal relay, the estimation errors remain the same as $D / \tau$ changes. The saturation relay, however, shows a smaller estimation error in $\mathrm{K}_{\mathrm{u}}$ for the system with a smaller $\mathrm{D} / \tau$ ratio (i.e., systems with long time constant). The results are just the opposite for the estimation of $P_{u}$, as shown in Figure 4. Furthermore, we can improve the estimation in $\mathrm{K}_{\mathrm{u}}$ by reducing the slope of the saturation relay, as shown in Figure 5. However, it should be emphasized that if the slope $\left(\mathrm{k}<\mathrm{K}_{\mathrm{u}}\right)$ is too small, the relay feedback will fail to generate a sustained oscillation.

Up to this point, the results come from the study of first order plus time delay systems. On some occasions, higher order systems are encountered and third-order systems are used to illustrate the effects of hysteresis. Figure 6 reveals that hysteresis leads to an overestimation in the ultimate gain and the offsets in the estimation are exactly the same as that of the first-order system (i.e., Figure 3) for the ideal relay. Qualitative similar estimation errors are observed for the saturation relay as shown in Figure 6 (e.g., comparing dashed lines in Figures 3 and 6). Actually, this is within one's expectation, since a hysteresis results in a discount in the relay height and, without any compensation, this simply overestimates $K_{u}$. The results can be summarized as follows.

(1) Relay feedback tests overestimate $K_{u}$ for actuators with hysteresis and relative errors increase with the DB. 

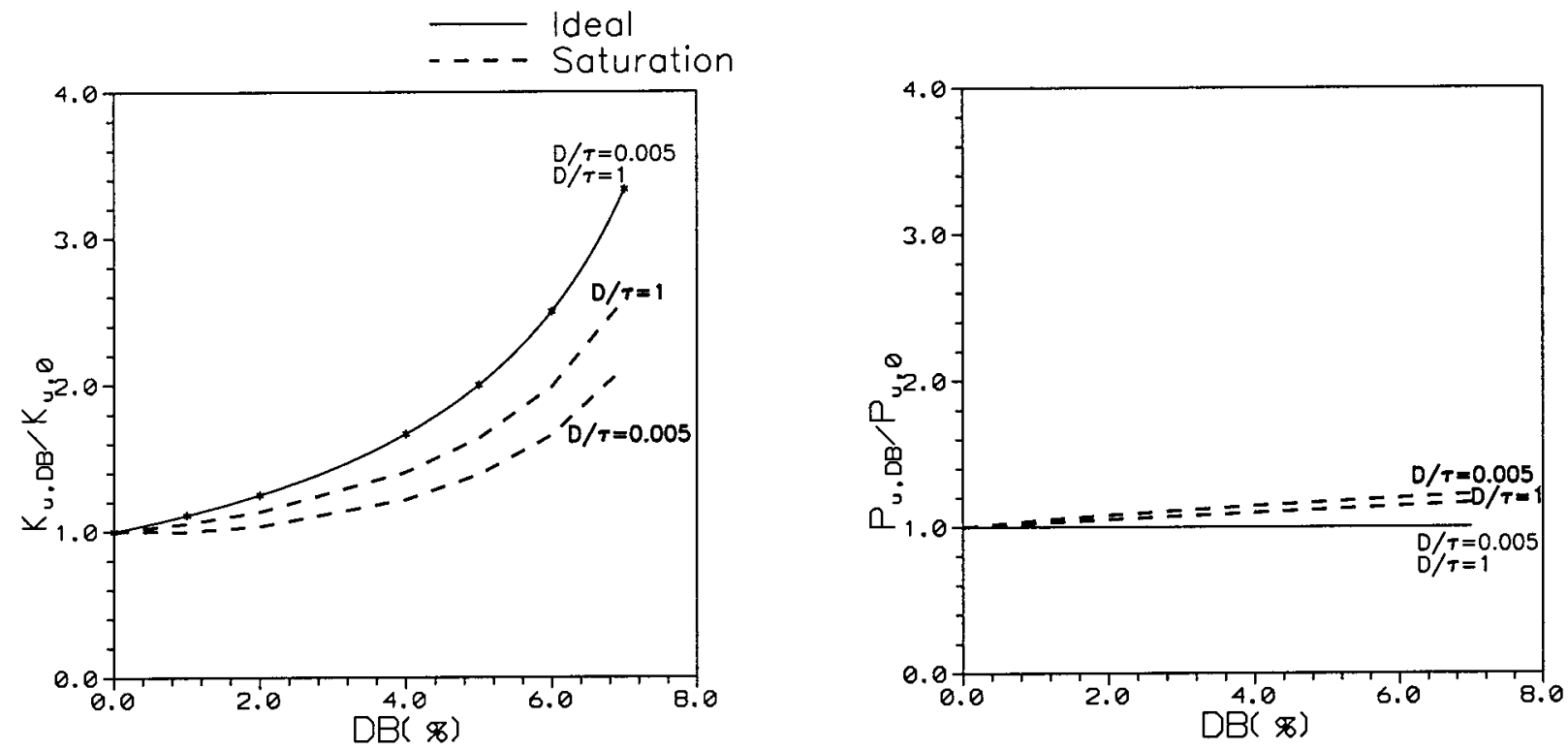

Figure 6. Effects of hysteresis width (DB) on estimation errors for ideal and saturation relays for third-order system with different $\mathrm{D} / \tau$ ratios.

This is generally true especially for the ideal and saturation relays (Figures 3 and 6).

(2) The saturation relay improves the estimation error in $\mathrm{K}_{\mathrm{u}}$ over the ideal relay. Moreover, the smaller the slope, the larger the margin of improvement (Figure 5).

(3) The saturation relay gives a better estimate in $\mathrm{K}_{u}$ for systems with a small $\mathrm{D} / \tau$ ratio (Figure 4 ).

(4) $\mathrm{F}$ or an ideal relay, the estimation error of $\mathrm{K}_{\mathrm{u}}$ remains the same for different $D / \tau$ ratios and the estimate of $\mathrm{P}_{\mathrm{u}}$ is not affected by the hysteresis (Figure 4).

Actually, for the ideal relay, the estimation error of $\mathrm{K}_{\mathrm{u}}$ can be expressed analytically in terms DB and $\mathrm{h}$. By comparing the ultimate gain using the assumed and true relay heights, the relative error in the estimation of $\mathrm{K}_{\mathrm{u}}$ can be computed. From eq 2, we have

$$
\frac{\mathrm{K}_{\mathrm{u}, \mathrm{DB}}}{\mathrm{K}_{\mathrm{u}}}=\frac{\mathrm{h}}{\mathrm{h}-\frac{\mathrm{DB}}{2}}
$$

where $K_{u}$ is the ultimate gain without hysteresis and $\mathrm{K}_{\mathrm{U}, \mathrm{DB}}$ is the ultimate gain under hysteresis actuator with a width DB. Since the true rel ay height is lowered by a factor of $D B / 2$, we subsequently overestimate the steady-state gain as well as the ultimate gain (the information is concealed by the hysteresis). Despite the fact that the saturation relay is more robust with respect to hysteresis actuator, the estimation error of $\mathrm{K}_{\mathrm{u}}$ can still be as large as $60 \%$ for a first-order system with $\mathrm{D} / \tau=1$ and $\mathrm{DB}=5 \%$. Therefore, it is necessary to provide remedial action for systems with imperfect actuators.

\section{I dentifications}

3.1. Two-step Procedure. Conventionally, the width of the hysteresis (DB) can be identified from bump tests or ramp tests. ${ }^{2}$ In the bump test, a series of step changes are made and hysteresis can be observed from the steady-state error resulting from opposite direction step changes (Figure 7A). Provided with the steady-state gain, the DB can be calculated from the steady-state error. For systems with long time constant, the bump test can be time-consuming. Another approach is to ramp the control output up first followed by a downward ramp (Figure 7B). The width of the hysteresis can be observed from the plot of $y$ and $u_{c o}$ as shown in Figure 7B. For linear systems, the width (DB) is simply the gap in between. But for nonlinear system, the gap may not be quite as obvious as shown in a later section.

If the width of the hysteresis is available, we can use the inverse of the hysteresis to adjust the shape of the relay. The inverse of the hysteresis can be expressed analytically. ${ }^{13}$

$$
\mathrm{u}_{\mathrm{co}}^{\prime}(\mathrm{t})=\frac{\mathrm{u}_{\mathrm{co}}(\mathrm{t})}{\mathrm{m}}+\chi_{\mathrm{r}}(\mathrm{t}) \mathrm{c}_{\mathrm{r}}+\chi_{\mathrm{l}}(\mathrm{t}) \mathrm{c}_{\mathrm{I}}
$$

with

$$
\begin{aligned}
& \chi_{r}(t)=\left\{\begin{array}{cc}
1 & \text { if } u_{c o}(t)>u_{c o}(t-1) \text { or } u_{c o}(t)= \\
& u_{c o}(t-1) \text { and } \chi_{r}(t-1)=1 \\
0 & \text { otherwise }
\end{array}\right. \\
& \chi_{1}(\mathrm{t})=\left\{\begin{array}{cc}
1 & \text { if } \mathrm{u}_{\mathrm{co}}(\mathrm{t})<\mathrm{u}_{\mathrm{co}}(\mathrm{t}-1) \text { or } \mathrm{u}_{\mathrm{co}}(\mathrm{t})= \\
& \mathrm{u}_{\mathrm{co}}(\mathrm{t}-1) \text { and } \chi_{1}(\mathrm{t}-1)=1 \\
0 & \text { otherwise }
\end{array}\right.
\end{aligned}
$$

Figure 8 shows corresponding relays if we have the information about the hysteresis. For the ideal relay, we simply increase the relay height by a factor of $D B /$ 2 , i.e., relay height $=h+(D B / 2)$. For the saturation relay, the shape of the relay can also be modified to accommodate the hysteresis (Figure 8B). Since the inverse of the hysteresis canceled out the effect of imperfect actuator, as expected, correct ultimate properties can be obtained using the modified relay (Figure 8). Note that the modified relays in Figure 8 provide the exact counter measures to overcome the hysteresis problems. Despite the fact the effect of hysteresis can be compensated for by using the modified relays, we still need two experiments to complete the procedure, finding the width of hysteresis followed by a relay feedback test.

3.2. Si multaneous Identification. Instead of identifying the hysteresis width and ultimate properties 
(A)
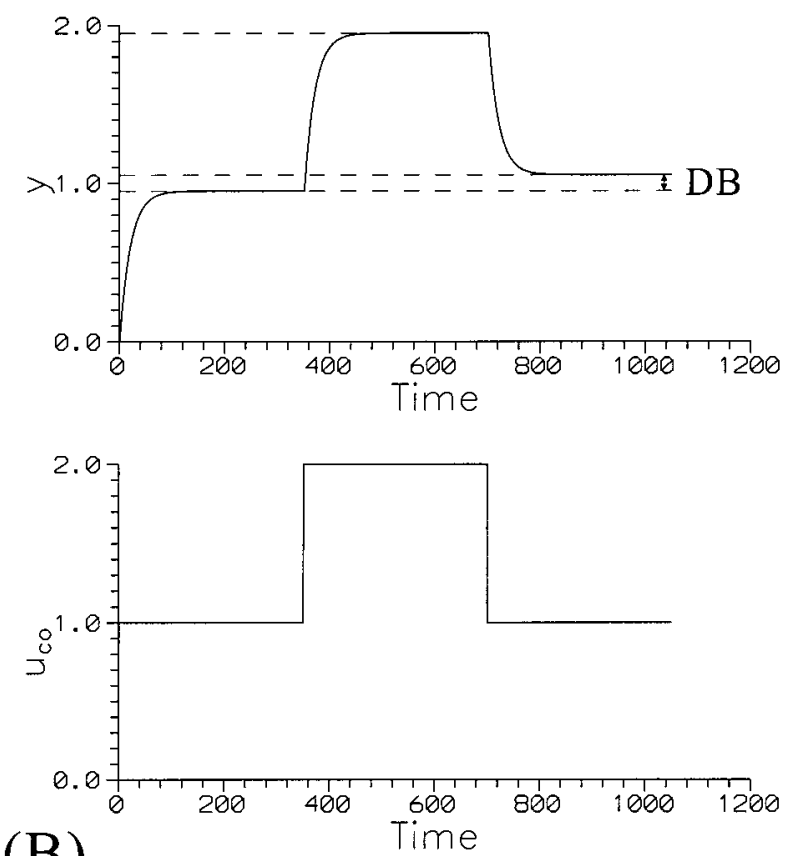

(B)
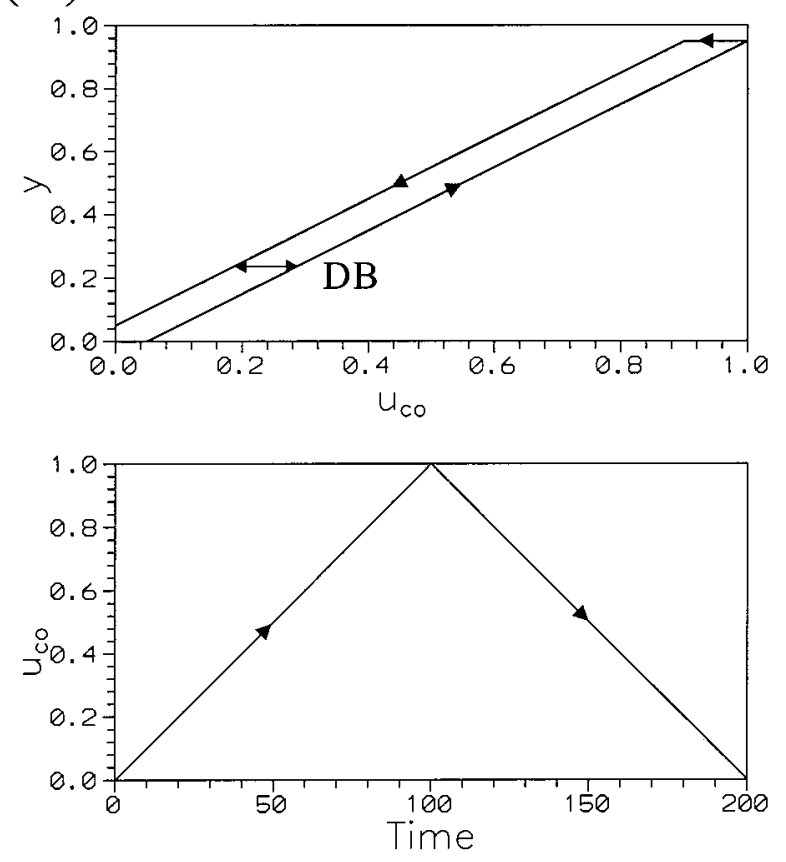

Figure 7. Identification of hysteresis using (A) bump test and (B) ramp test.

separately, it is possible carry out the experiment in one step. As mentioned earlier, the reason the ideal relay overestimates the ultimate gain under hysteresis (with a width DB) is that the actual output of the relay $(u)$ is reduced by $\mathrm{DB} / 2$ as the result of a hysteresis. For example, in Figure $2 \mathrm{~A}$, the actual actuator positions are

$$
\mathrm{u}=\mathrm{h}-\frac{\mathrm{DB}}{2} \text { or }-\left(\mathrm{h}-\frac{\mathrm{DB}}{2}\right)
$$

The amplitude of oscillation (a) was generated from this relay height. Unfortunately, we still use $h$ to compute the ultimate gain using eq 2 . This consequently results in a much larger $\mathrm{K}_{\mathrm{u}}$. This insight leads to a new
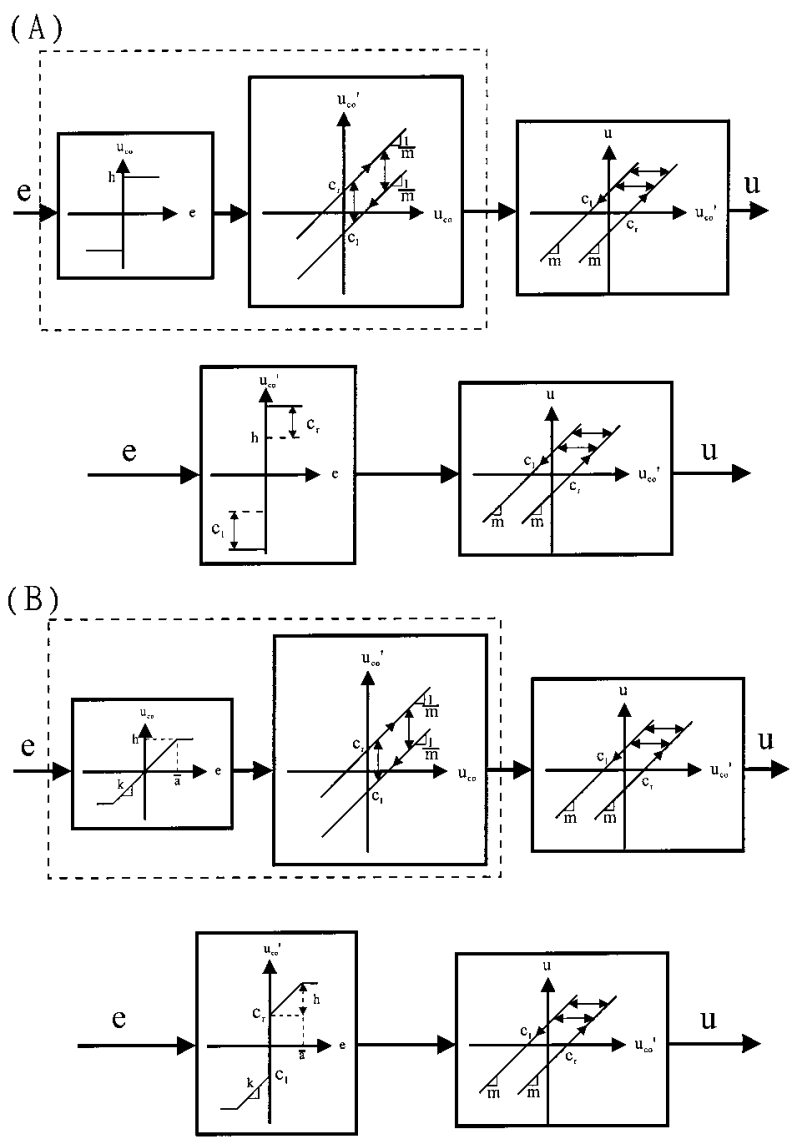

Figure 8. Resultant relays by combining the original relay with the inverse of hysteresis for (A) ideal relay and $(B)$ saturation relay.

relay feedback procedure for the simultaneous identification of DB and $\mathrm{K}_{\mathrm{u}}$. If we carry out a relay feedback test using two different relay heights $h_{1}$ and $h_{2}$, this results in sustained oscillations with two amplitudes $a_{1}$ and $a_{2}$. As the result of possible hysteresis, the actual relay heights are $h_{1}-D B / 2$ and $h_{2}-D B / 2$. From sustained oscillations, we have

$$
\frac{a_{1}}{a_{2}}=\frac{h_{1}-\frac{D B}{2}}{h_{2}-\frac{D B}{2}}
$$

Therefore, the width of the hysteresis (DB) can be calculated from:

$$
\frac{D B}{2}=\frac{a_{2} h_{1}-a_{1} h_{2}}{a_{2}-a_{1}}
$$

Once DB becomes available, the ultimate gain can be computed from:

$$
K_{u}=\frac{4\left(h_{i}-\frac{D B}{2}\right)}{\pi a_{i}}
$$

where $\mathrm{i}=1$ or 2 . The ultimate period $\left(\mathrm{P}_{\mathrm{u}}\right)$ can be read directly from the responses, since it will not be affected by the hysteresis (e.g., Figure 3). The procedure can be summarized as the following. 

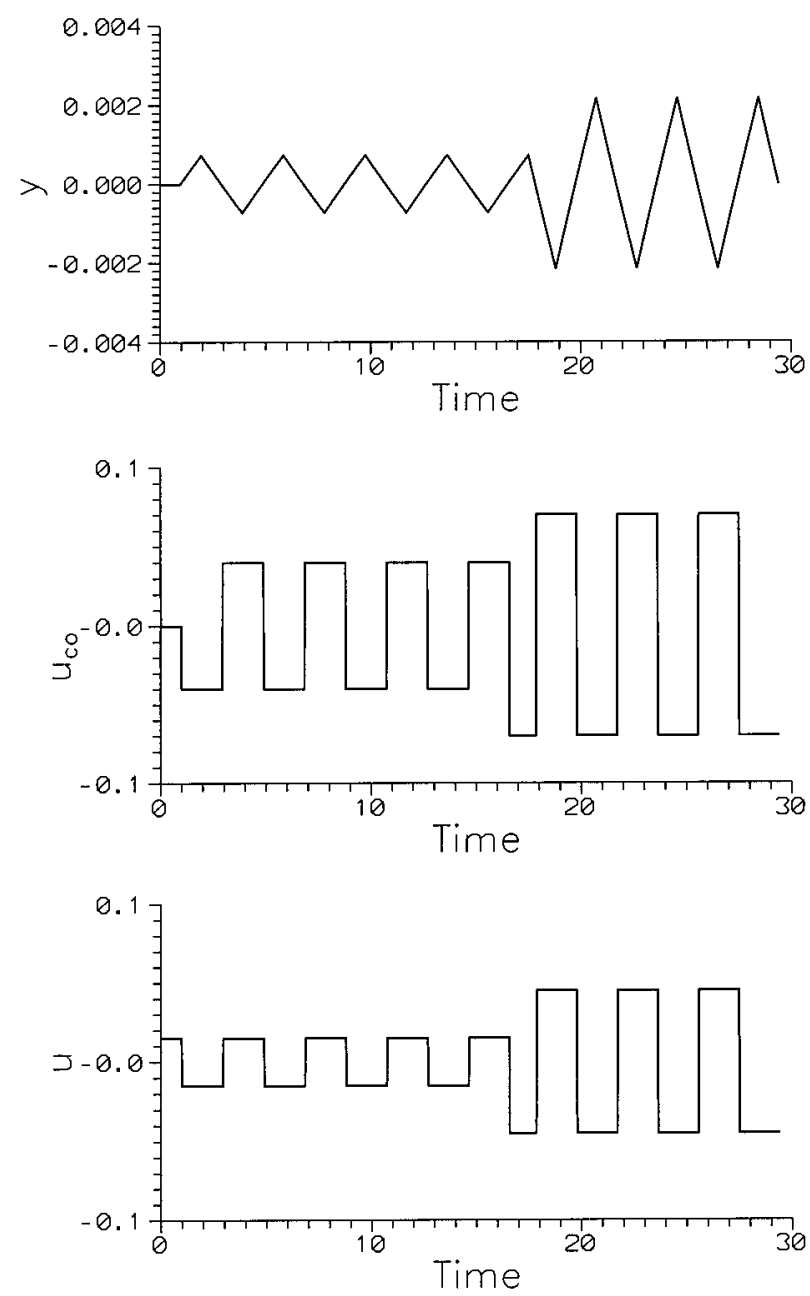

Figure 9. Proposed relay feedback tests on a first-order plus time delay system with $\mathrm{h}_{1}=4 \%$ and $\mathrm{h}_{2}=7 \%$.

(1) Select a relay height $h_{1}$ (e.g., 3-7\%).

(2) Perform a relay feedback test, and when the system reaches sustained oscillation, read off the amplitude of oscillation $\left(\mathrm{a}_{1}\right)$ and ultimate period $\left(\mathrm{P}_{\mathrm{u}}\right)$.

(3) Increase the relay height by $2-4 \%\left(h_{2}\right)$ and read off the amplitude of oscillation $\left(\mathrm{a}_{2}\right)$.

(4) Compute the width of hysteresis (DB) from eq 13 and the ultimate gain from eq 14.

In step 1, the relay height $\left(\mathrm{h}_{1}\right)$ should be greater than DB/2 to prevent failure in the experiment, since the actual relay height is discounted by $D B / 2$. In step 3, only a small increase from $h_{1}$ (e.g., 2-4\%), generally, can provide the resolution we need to differentiate $a_{1}$ and $a_{2}$ (i.e., we will have a net effect from the relay height change). Notice that the ultimate periods should be the same for relay with different heights for linear systems. Any deviation from the equality is an indication of process nonlinearity, nonuniform hysteresis width, etc.

\section{Applications}

Since the two-step procedure, in theory, will give a perfect estimation in ultimate properties (provided with exact value DB), the second approach is tested here. Let us use two linear systems and one nonlinear process to illustrate the simultaneous identification procedure for systems with imperfect actuators. Comparisons are made between conventional and proposed relay feedback tests.

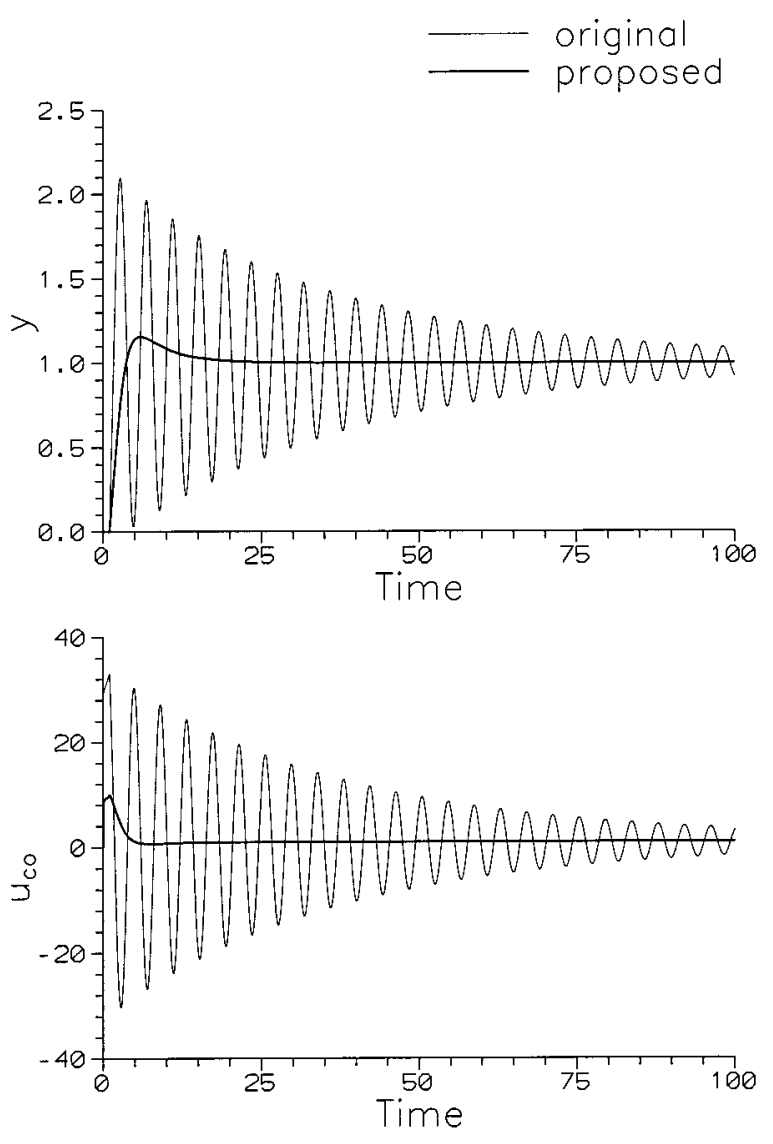

Figure 10. Set point responses using controller settings from the original and proposed relay feedback tests.

4.1. Linear Systems. 4.1.1. Noise-F ree System. Let use a transfer function model to illustrate the identification procedure. First consider a noise-free linear model.

Example 1. First-order plus time delay system:

$$
G(s)=\frac{e^{-s}}{20 s+1}
$$

Suppose the actuator exhibits hysteresis with a width $\mathrm{DB}=5 \%, \mathrm{~m}=1$ and $|\mathrm{c}||=| \mathrm{c}_{\mathrm{r}} \mid$. An ideal relay feedback with $\mathrm{h}=5 \%$ gives $\mathrm{K}_{\mathrm{u}}=52.9$, which is almost $100 \%$ larger than the nominal value $\left(\mathrm{K}_{\mathrm{u}}=26.5\right.$, e.g., eq 7$)$. Following the proposed procedure, we starts with $\mathrm{h}_{1}=$ $4 \%$. From process responses (Figure 9 ), we obtain $a_{1}=$ 0.00072 and $\mathrm{P}_{\mathrm{u}}=3.85$. After a few oscillations the relay height is increased by $3 \%\left(h_{2}=7 \%\right)$, as shown in Figure 9. The amplitude of oscillation then becomes $a_{2}=$ 0.00217 and $P_{u}$ stays the same. The ultimate period indicates that this is a linear system. Then, we proceed to calculate the width of hysteresis using eq 13.

$$
\frac{\mathrm{DB}}{2}=\frac{0.00217 \times 0.04-0.00072 \times 0.07}{0.00217-0.00072}=0.0251
$$

This is a very good estimate of DB (i.e., $4 \%$ error). Once DB is available, the ultimate gain is calculated immediately from eq 14. That gives $K_{u}=26.35$. A PI controller is used to control the linear system with an imperfect actuator. The controller is tuned using the modified Ziegler - Nichols method, $\mathrm{K}_{\mathrm{c}}=\mathrm{K}_{\mathrm{u}} / \mathrm{B}$ and $\tau_{\mathrm{l}}=2$ $\mathrm{P}_{\mathrm{u}}{ }^{18}$ Simulation results show that the proposed procedure gives satisfactory responses under an imperfect actuator (Figure 10). On the other hand, since the 

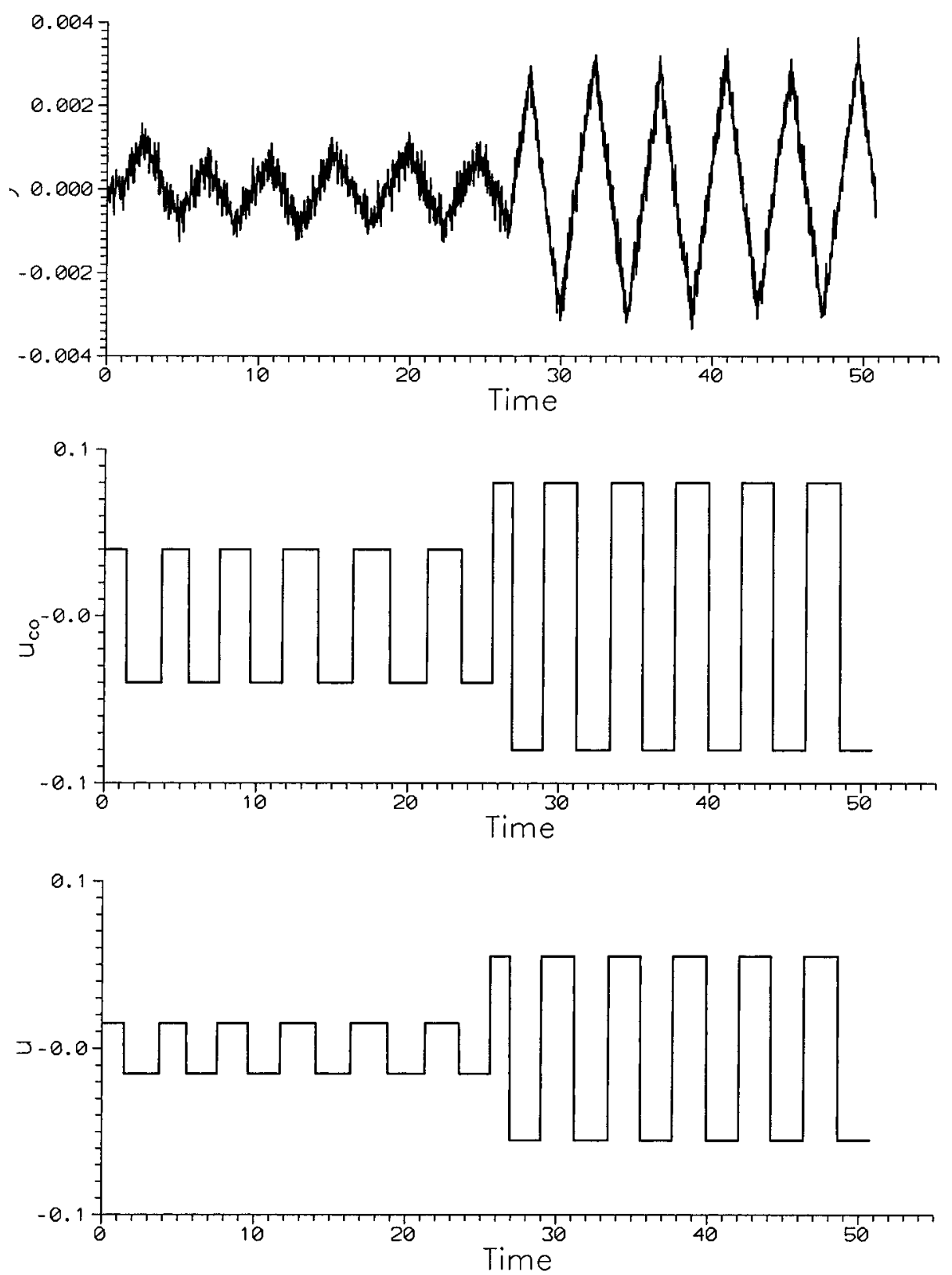

Figure 11. Proposed relay feedback tests on a first-order plus time delay system with measurement noise (NSR $=22 \%$ ).

conventional relay feedback does not realize the existence of hysteresis, oscillatory set point response is observed.

This example clearly indicates that it is possible to identify the width of a hysteresis and ultimate properties simultaneously. Moreover, the estimates appear to be quite accurate compared to the case of a perfect actuator. Any practical identification procedure should be robust with respect to process and/or measurement noises.

4.1.2. Systems with Measurement Noise. The proposed method is tested against measurement noise. In the context of system identification, the noise-tosignal ratio (NSR) can be expressed as ${ }^{16}$

$$
\mathrm{NSR}=\frac{\text { mean }(\text { abs }(\text { noise }))}{\text { mean(abs(signal)) }}
$$

where abs( $\cdot)$ denotes the absolute value and mean $(\cdot)$ represents the mean value.
Example 2. Example 1 with measurement noise: Consider the case of NSR $=22 \%$. Again, assume the actuator shows hysteresis with a width $\mathrm{DB}=5 \%$. First we perform a relay feedback test with $h_{1}=4 \%$ followed by a second test with $h_{2}=8 \%$ (Figure 11 ). N otice that it is a common practice to employ a relay with hysteresis for systems with significant measurement noise. ${ }^{18} \mathrm{Here}$, the width of the hysteresis of the relay is set to twice of the standard deviation of the noise. F rom system output (Figure 9), we obtain $a_{1}=0.00081$ and $a_{2}=0.00281$. The width (DB) can be computed immediately from eq 13 and, subsequently, the ultimate gain is calculated immediately from from eq 14 . This results in DB = $4.76 \%$ and $K_{u}=25.46$. Notice that the estimated ultimate period is $15 \%$ higher than the nominal value. Table 1 compares the estimates for systems with and without noise. The results show that the proposed method works reasonably well under noisy condition. As expected, as the noise level decreases (e.g., NSR = $10 \%)$, a slightly better estimate of DB can be obtained, 
Table 1. Estimates of Width of Hysteresis and Ultimate Properties under Different Noise-to-Signal Ratios (NSR)

\begin{tabular}{cccc}
\hline $\mathrm{NSR}(\%)$ & $\mathrm{DB}_{\text {estimated }} / \mathrm{DB}_{\text {true }}$ & $\mathrm{K}_{\mathrm{u}}{ }^{\mathrm{a}}$ & $\mathrm{P}_{\mathrm{u}}{ }^{\mathrm{a}}$ \\
\hline 0 & $5.02 / 5.00$ & 26.35 & 3.85 \\
10 & $4.86 / 5.00$ & 26.65 & 4.07 \\
22 & $4.76 / 5.00$ & 25.46 & 4.32 \\
a True valves: $\mathrm{K}_{\mathrm{u}}=26.46$ and $\mathrm{P}_{\mathrm{u}}=3.85$. &
\end{tabular}

Table 2. Estimates of Width of Hysteresis and Ultimate Properties for Different Relay Heights $\left(h_{1}\right.$ and $\left.h_{2}\right)$ under 22\% Noise-to-Signal Ratio

\begin{tabular}{cccc}
$\mathrm{h}_{1} / \mathrm{h}_{2}(\%)$ & $\mathrm{DB}_{\text {estimated }} / \mathrm{DB}_{\text {true }}$ & $\mathrm{K}_{\mathrm{u}}{ }^{\mathrm{a}}$ & $\mathrm{P}_{\mathrm{u}^{\mathrm{a}}}$ \\
\hline $3 / 6$ & $4.95 / 5.00$ & 25.79 & 4.08 \\
$3 / 8$ & $4.92 / 5.00$ & 25.56 & 4.58 \\
$3 / 10$ & $4.96 / 5.00$ & 25.47 & 4.23 \\
$4 / 6$ & $4.34 / 5.00$ & 26.50 & 4.65 \\
$4 / 8$ & $4.76 / 5.00$ & 25.46 & 4.32 \\
$4 / 10$ & $4.56 / 5.00$ & 25.46 & 4.15
\end{tabular}

a True valves: $\mathrm{K}_{\mathrm{u}}=26.46$ and $\mathrm{P}_{\mathrm{u}}=3.85$.

as shown in Table 1. Moreover, set point responses of the noisy system are practically the same as in Figure 9.

Another factor affects the accuracy in the estimation is the choice of $h_{1}$ and $h_{2}$. In theory, for linear systems, the results should remain the same regardless of the selection of relay heights. However, the accuracy of estimation may vary for systems with measurement noise. Again, consider the case with a noise level of NSR $=22 \%$. F or a range of $h_{1}$ and $h_{2}$, the simultaneous procedure gives fairly consistent results, as shown in Table 2. That is, for the suggested ranges of relay heights, little difference is observed for different choices of $h_{1}$ and $h_{2}$.

Example 2 clearly demonstrates that the simultaneous identification procedure is quite robust with respect to measurement noise. However, the user should be cautious when dealing with measurement noise. First, the amplitude for each oscillation is obtained by taking the average of several points around the peak (seven data points in this case) and the amplitude of oscillation $\left(\mathrm{a}_{\mathrm{i}}\right)$ is the average from a few oscillations. The ultimate period $\left(\mathrm{P}_{\mathrm{u}}\right)$ is also an average value from cycling. Certainly, the noise-handling method should also be applied to the conventional relay feedback test. Moreover, the selection of the relay heights has little impact on the accuracy of the estimation for the linear system studied.

4.1.3. Load Disturbance. Low-frequency load change is another important issue any practical identification procedure has to face. A relay feedback method was proposed to overcome load disturbance when identifying ultimate gain and ultimate frequency. ${ }^{18}$ It was proven effective for perfect actuators. Here, the proposed method is extended to handle actuators with hysteresis under load changes.

Let us use the first-order plus time delay system (example 1) to illustrate the identification under load disturbance. Consider the foll owing load transfer function.

$$
G_{L}(s)=\frac{e^{-0.5 s}}{10 s+1}
$$

Again, the actuator shows hysteresis with a width of $5 \%(\mathrm{DB}=5 \%)$. A step load disturbance comes into the system when a relay feedback test with $\mathrm{h}=4 \%$ is performed (Figure 12) and it gives an unbalanced period of oscillation (e.g., time $<47$ in Figure 12). We continue the procedure in section 3 with a second relay feedback test $(\mathrm{h}=7 \%)$, and $\mathrm{K}_{\mathrm{u}}$ and $\mathrm{P}_{\mathrm{u}}$ can be computed from eq 2 as shown in Figure 12. Following the proposed
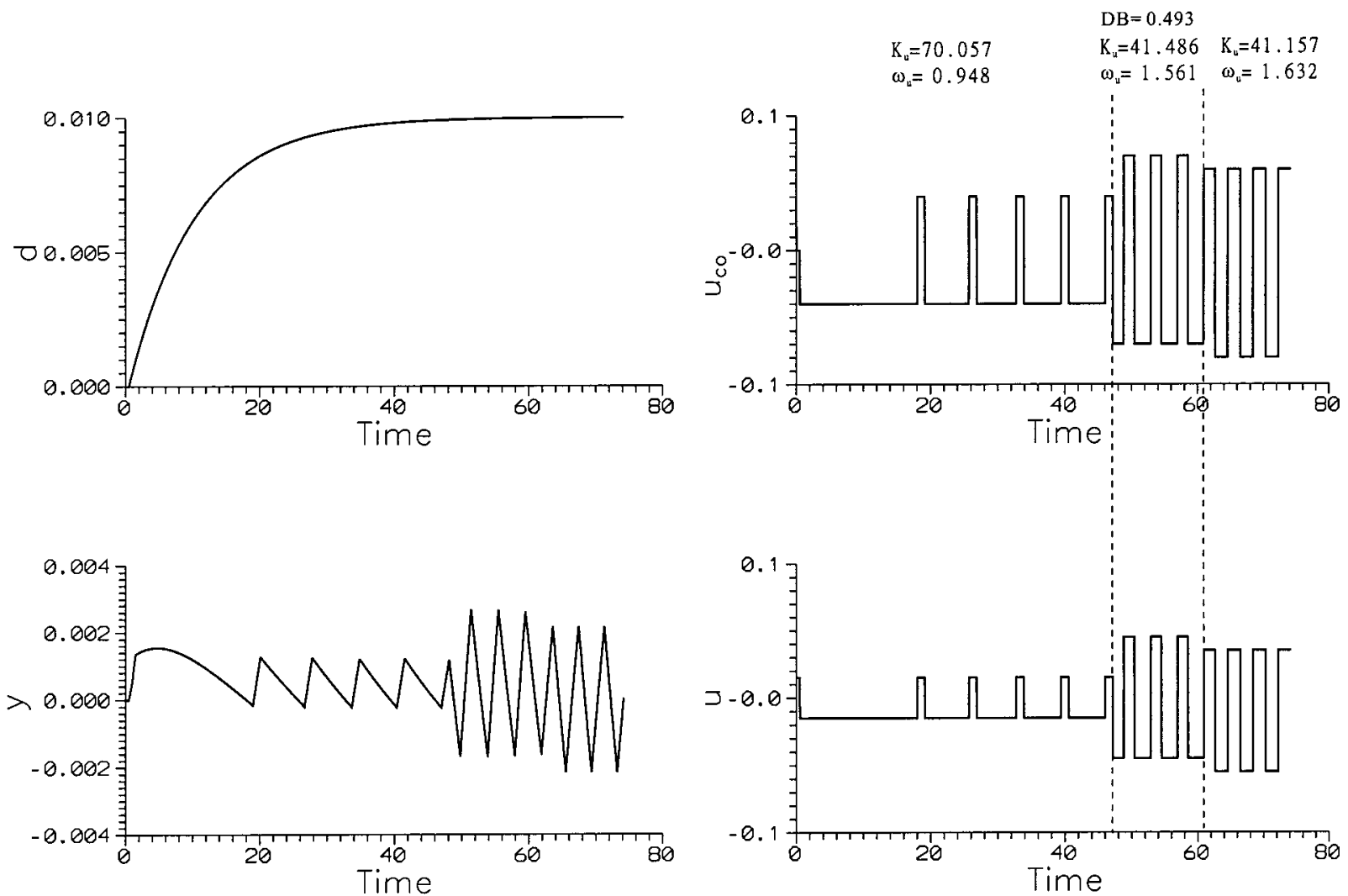

Figure 12. Extended relay feedback tests under step load change for a first-order plus time delay system with $h_{1}=4 \%$ and $h_{2}=7 \%$. 


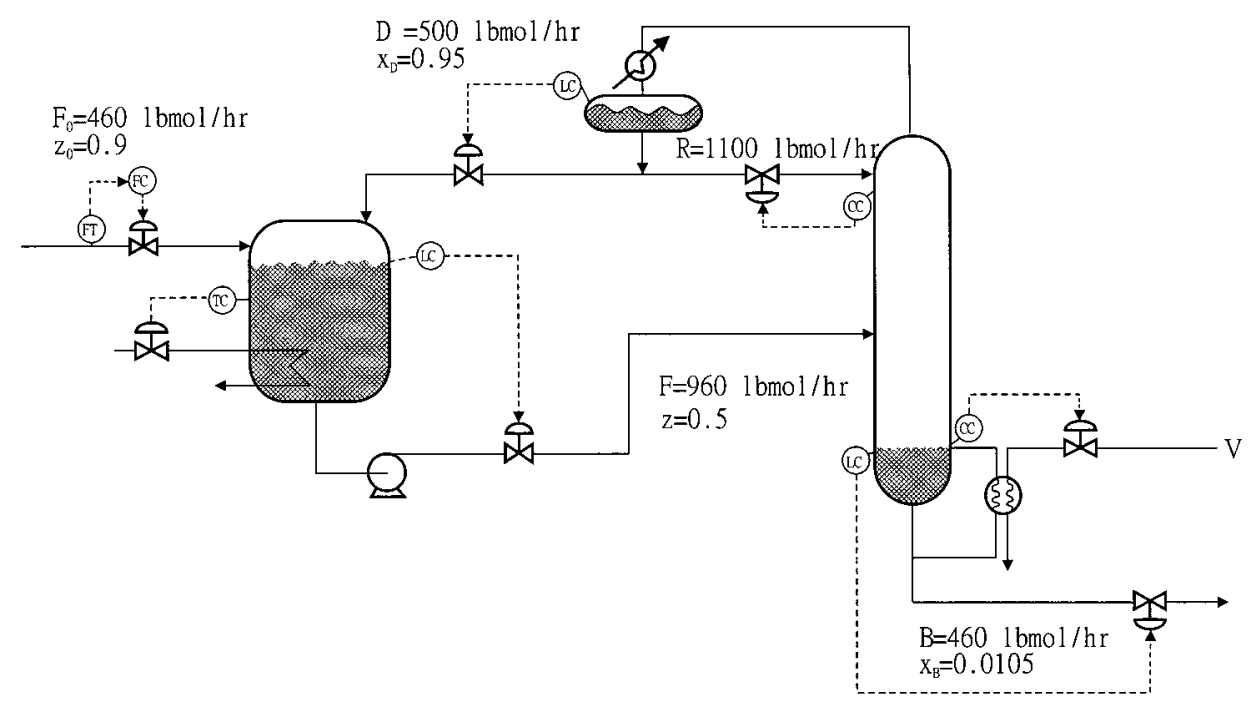

Figure 13. Recycle plant with an $\mathrm{R}-\mathrm{V}$ control structure on the distillation column.
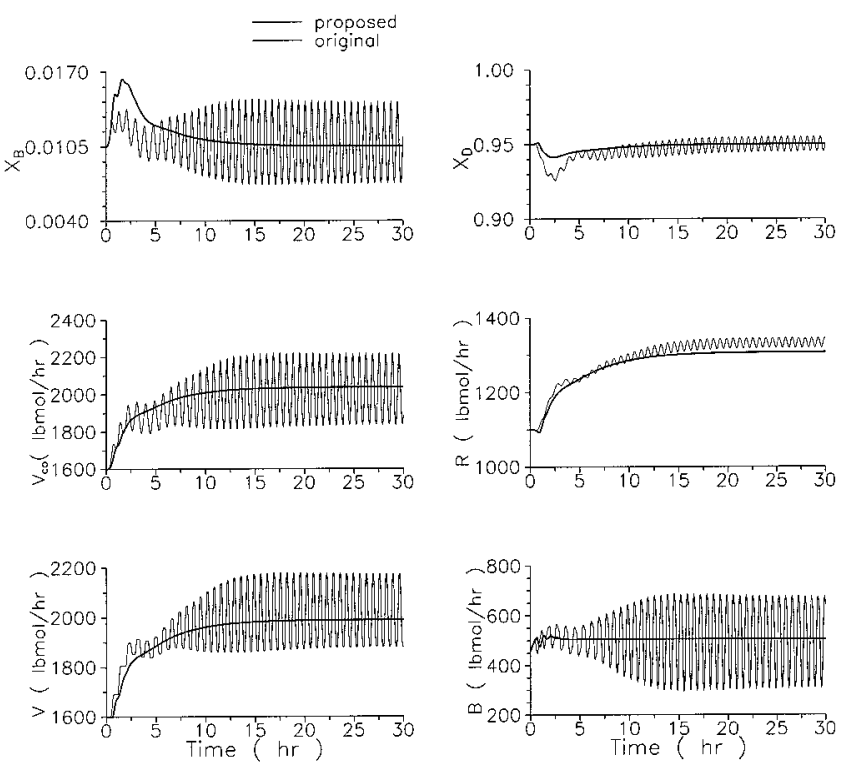

Figure 14. Step responses of a recycle plant with an imperfect actuator in the bottom loop for $10 \%$ production rate increase using controller settings from proposed and original autotuning methods.

procedure, the width of the hysteresis can be computed from eq 13.

$$
\frac{\mathrm{DB}}{2}=\frac{0.00215 \times 0.04-0.00073 \times 0.07}{0.00215-0.00073}=0.0246
$$

This gives $\mathrm{DB}=4.92 \%$, which is a fairly good estimation, and the ultimate gain is corrected according to eq 14. The corrected ultimate gain becomes $\mathrm{K}_{\mathrm{u}}=$ 26.90. Notice that, up to this point, we just follow the proposed procedure and biased oscillations are observed as the result of load change (e.g., time $<60$ in Figure 12). But fairly good estimates in $\mathrm{DB}, \mathrm{K}_{\mathrm{u}}$, and $\mathrm{P}_{\mathrm{u}}$ are obtained as shown in Figure 12 (e.g., comparing with the true values in Table 1). We can restore a symmetric oscillation using a biased relay, and the biased value $\left(\delta_{0}\right)$ is ${ }^{18}$

$$
\delta_{0}(\mathrm{~s})=-\frac{\mathrm{h} \Delta \mathrm{a}}{\mathrm{a}}
$$

where $\Delta a$ is the biased value of the output (y). Once the biased relay is installed and the output oscillation becomes symmetric, a little better estimation of $\mathrm{K}_{\mathrm{u}}$ and $\mathrm{P}_{\mathrm{u}}$ can be achieved (Figure 12). The result, again, illustrates the effectiveness of the proposed procedure under low-frequency disturbances.

4.2. Nonlinear Process. The third example is the reactor/separator plant studied by $\mathrm{Wu}$ and $\mathrm{Yu}^{17}$ The feed to the system is the reactant $A$ and the al most highpurity ( 0.9895 mole fraction) product $B$ is taken out from the bottoms of the distillation column. The conventional control structure is employed (Figure 13), and controller settings are obtained using the sequential autotuning approach of Shen and $Y u .{ }^{11}$ This is a multivariable system where the product quality $\left(X_{B}\right)$ is maintained by changing the vapor boilup (V) and the distillate composition is control led by varying the reflux flow (R). The nominal production rate is $B=460 \mathrm{lb} \mathrm{mol} / \mathrm{h}$.

Because of wear, the steam valve exhibits hysteresis with a width of $6 \%$. Not recognizing this fact, controller settings (Table 2 ) from the sequential autotuning simply lead to unacceptable closed-loop responses for a $10 \%$ production rate increase, as shown in Figure 14.

4.2.1. Two-Step Procedure. The ramp test (Figure 7B) is employed to find the width of the hysteresis (DB). For the slow chemical process, it takes an extremely long time (100 hrs as shown in Figure 15$)$ to complete the ramp test while a reasonable value for the DB is found. Following the standard procedure, the width of the hysteresis can be observed from the plot of the controlled variable $\left(\mathrm{X}_{\mathrm{B}}\right)$ versus controller output $\left(\mathrm{V}_{\mathrm{co}}\right.$, Figure 16). This gives a DB of 5.6\% (a little lower than the true value of $6 \%$ ). It is interesting to note that nonlinear characteristics are observed in the ramp test (F igure 16) as oppose to the linear system (Figure 7B). Once DB is available, we can compensate the offset from the hysteresis by adjusting the relay height (Figure 8). After the compensated relay feedback tests, the controller settings immediately become available as shown in Figure 15. Despite being able to correctly identify ulti mate properties, the ramp test part of the procedure is simply too time-consuming and may not be a good choice for slow chemical processes. On the contrary, the relay feedback type of test becomes attractive.

4.2.2. Simultaneous Procedure. The simultaneous approach uses consecutive relay feedback tests to identify the width of the hysteresis as well as the ultimate properties. Following the modified Ziegler-Nichols tun- 

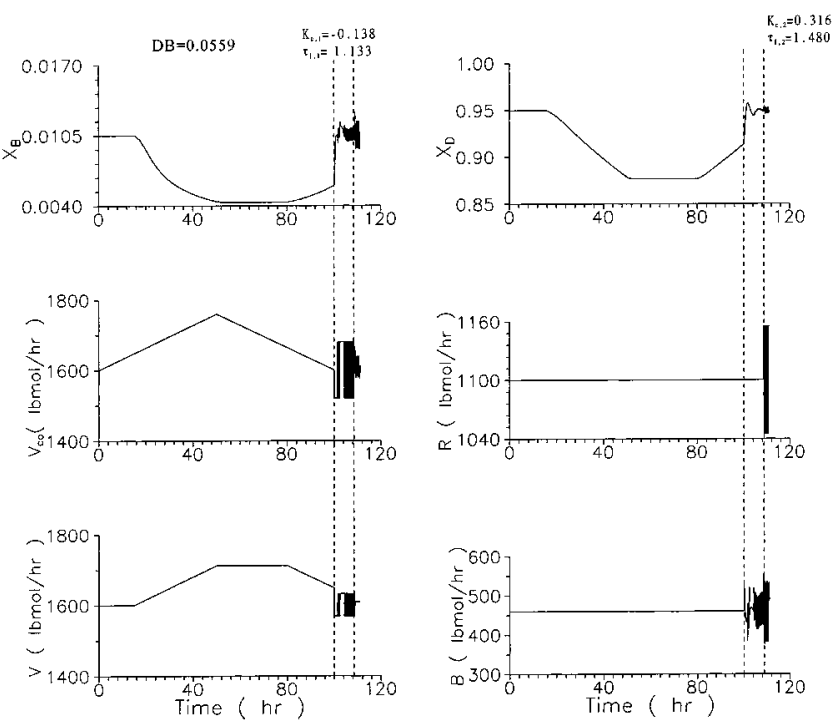

Figure 15. Ramp test followed by relay feedback tests for a recycle plant with an imperfect actuator in the bottom loop.

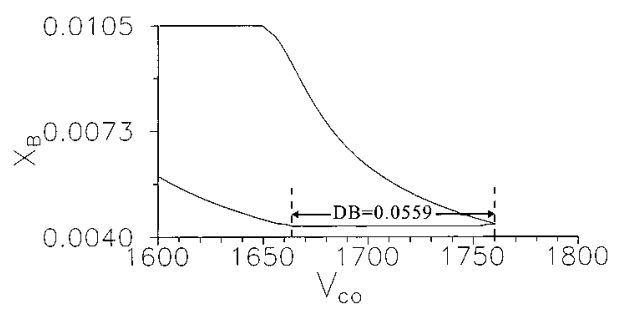

Figure 16. Plot of the controlled variables and controller output from the ramp test to identify the width of the hysteresis.

Table 3. Controller Parameters Using Different Autotuning Methods for a Recycle Plant under Various Situations of I mperfect Valves

\begin{tabular}{lccccc}
\hline & \multicolumn{2}{c}{$\mathrm{DB}_{\text {estimated }} / \mathrm{DB}_{\text {true }}(\%)$} & & \multicolumn{2}{c}{$\mathrm{K}_{\mathrm{d}} \tau_{l^{\mathrm{b}}}{ }^{\mathrm{b}}$} \\
\cline { 2 - 3 } \cline { 5 - 6 } & bottom & top & & $\mathrm{X}_{\mathrm{B}}{ }^{\mathrm{a}}$ & $\mathrm{X}_{\mathrm{D}}{ }^{\mathrm{a}}$ \\
\hline Original & $-/ 0$ & $-/ 0$ & & $-0.126 / 1.116$ & $0.275 / 1.289$ \\
Original & $6 / 6$ & $-/ 0$ & & $-0.352 / 1.101$ & $0.121 / 1.350$ \\
Proposed & $6 / 6$ & $-/ 0$ & & $-0.128 / 1.122$ & $0.275 / 1.378$ \\
Original & $6 / 6$ & $5.9 / 6$ & & $-0.369 / 1.138$ & $0.169 / 1.360$ \\
Proposed & $6 / 6$ & $5.9 / 6$ & & $-0.127 / 1.124$ & $0.272 / 1.383$
\end{tabular}

a Transmitter spans: $x_{B}=0.021$ and $x_{D}=0.1$ mole fraction valve gains: twice nominal steady-state flow rate. ${ }^{b}$ In $h$.

ing, we can finds the controller parameters (Table 3 ). Figure 17 shows the sequence of autotuning when the steam valve ( $V$ shown in the graph) is imperfect. It takes less than $10 \mathrm{~h}$ to complete the tuning of top and bottoms loops (as oppose to more than $100 \mathrm{~h}$ for the two-step procedure). The new settings give good closed-loop performance (Figure 14) that is not too different from that when the steam valve does not have hysteresis. ${ }^{17}$ It should be noted that the actual opening of the steam valve $(\mathrm{V})$ is quite different from the control output $\left(\mathrm{V}_{\mathrm{co}}\right)$. It is clear that the behavior of the steam valve movement is far from sustained cycling as the result of hysteresis (Figure 17). The situation becomes worse if both the reflux and steam valves exhibit hysteresis. Figure 18 shows that a prolonged transient response during the tuning of the $x_{D}$ loop. Longer experimental time or, even worse, possible failure in experiment can be expected when more and more val ves in the systems showing hysteresis. Despite the fact that the settings from Figure 18 work almost as well as the previous case, the efficiency in the relay feedback test deteriorates quickly when the number of imperfect actuators in-
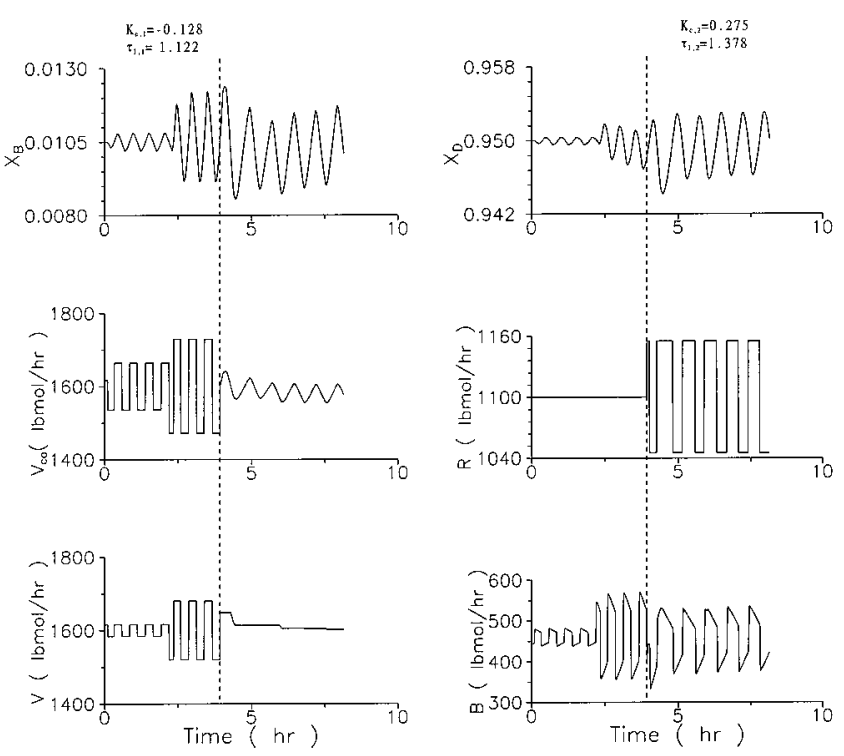

Figure 17. Proposed autotuning sequence for a recycle plant with an imperfect actuator in the bottom loop.
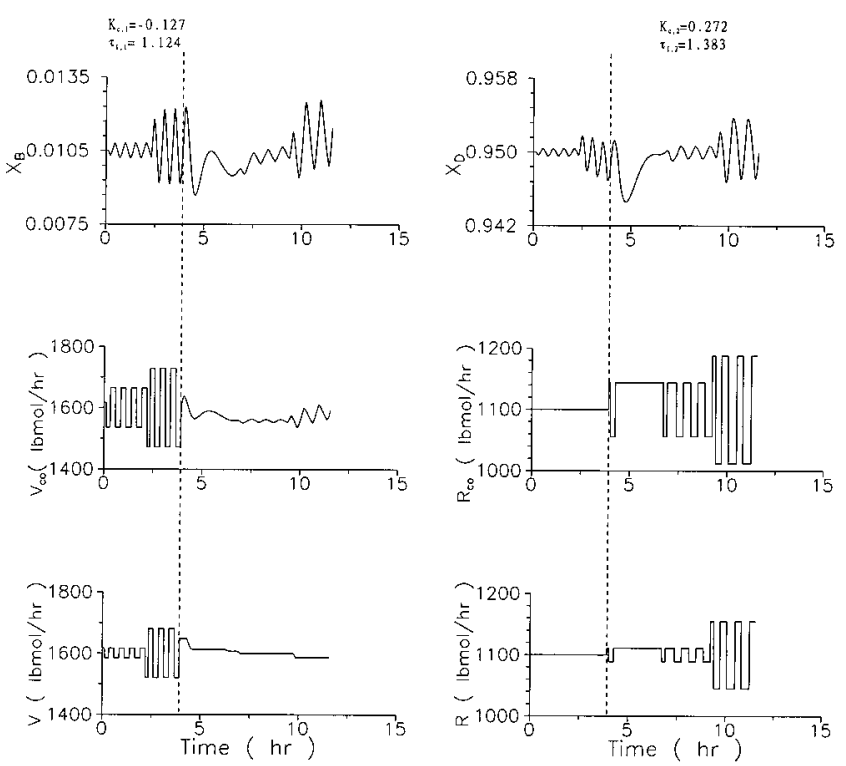

Figure 18. Proposed autotuning sequence for a recycle plant with imperfect actuators in both top and bottom loops.

creases. This implies, regardless of how smart the autotuner may be, that the best solution to handle imperfect actuators is to have the valves fixed or get a positioner.

\section{Conclusion}

Hysteresis is sometimes observed in pneumatic and piezoelectric actuators. Under relay feedback, the effects of actuator hysteresis on estimation errors are explored. Comparisons are made between the ideal and saturation relays. As expected, the ramp behavior of the saturation relay can alleviate the overestimate of $K_{u}$. If the width of hysteresis (DB) is available (e.g., estimated from bump test), the shapes of the relays can be modified to accommodate the imperfection and to provide better accuracy. Moreover, a procedure for simultaneous identification of the width of the hysteresis and ultimate properties is also proposed. Simulation results show that good estimates of ultimate properties can be obtained. It provides better reliability for relay feedback identi- 
fication and opportunities for improved control under imperfect actuators. Finally, a word of caution is in place: Regardless of how smart the autotuner is, the best approach to handle an imperfect actuator is to have it fixed.

\section{Nomenclature}

$\mathrm{a}=$ amplitude of oscillation

$c_{1}=$ width of the hysteresis toward left

$C_{r}=$ width of the hysteresis toward right

$\mathrm{D}=$ time delay

$\mathrm{DB}=$ width of hysteresis

$\mathrm{G}(\mathrm{s})=$ process transfer function

$\mathrm{G}_{\mathrm{L}}(\mathrm{s})=$ load transfer function

$\mathrm{h}=$ relay height

$\mathrm{K}_{\mathrm{p}}=$ steady-state gain

$\mathrm{K}_{\mathrm{u}}=$ ultimate gain

$\mathrm{K}_{\mathrm{u}, \mathrm{DB}}=$ computed ultimate gain (eq 2) under imperfect actuator

$\mathrm{m}=$ slope of the hysteresis

NSR $=$ noise-to-signal ratio

$\mathrm{P}_{\mathrm{u}}=$ ultimate period

$\mathrm{P}_{\mathrm{u}, \mathrm{DB}}=$ observed ultimate period under imperfect actuator

$\mathrm{u}=$ actual actuator position

$\mathrm{u}_{\mathrm{co}}=$ actuator position (when perfect)

$\mathrm{u}_{\mathrm{co}}^{\prime}=$ compensated $\mathrm{u}_{\mathrm{co}}$

$\mathrm{y}=$ process output

Greek Symbols

$\tau=$ time constant

$\omega_{\mathrm{u}}=$ ultimate frequency

\section{Acknowledgment}

This work was supported by the National Science Council of Taiwan.

\section{Literature Cited}

(1) Åström, K. J .; Hägglund, T. Automatic Tuning of Simple Regulators with Specifications on Phase and Amplitude Margins. Automatica 1984, 20, 645.

(2) Åström, K.J .; Hägglund, T. PID Controllers: Theory, Design and Tuning; Instrumentation Society of America: Research Triangle Park, 1995.
(3) Ender, D. B. Process Control Performance: Not as Good as You Think. Control Eng. 1993, 40, 180.

(4) Hersh, M. A.; I ohnson, M. A. A Study of Advanced Control Systems in the Workplace. Control Eng. Prac. 1997, 5, 771.

(5) Huang, H. P.; Chen, C. L.; Lai, C. W. Wang, G. B. Autotuning for Model-Based PID Controllers. AIChE J . 1996, 42, 2687.

(6) Kimura, T.; Hara, S.; Fujita, T.; Kagawa, T. Feedback Linearization for Pneumatic Actuator Systems with Static F riction. Control Eng. Prac. 1997, 5, 1385.

(7) Lin, Z. Robust Semi-global Stabilization of Linear Systems with Imperfect Actuators. Syst. Control Lett. 1997, 29, 215.

(8) Lewis, F. L.; Tim, W. K.; Wang, L. Z.; Li, Z. X. Deadzone Compensation in Motion Control Systems Using Adaptive Fuzzy Logic Control. IEEE Trans. Control Syst. Technol. 1999, 7, 731.

(9) Luyben, W. L.; Luyben, M. L. Essentials of Process Control; McGraw-Hill: New York, 1997.

(10) McMillan, G. K. Tuning and Control Loop Performance Instrument Society of America: Research Triangle Park, 1994.

(11) Shen, S. H.; Yu, C. C. Use of Relay-Feedback Test for the Automatic Tuning of Multivariable Systems. AIChE J . 1994, 40, 627.

(12) Shen, S. H.; Yu, H. D.; Yu, C. C. Use of Saturation-Relay Feedback for Autotune Identification. Chem. Eng. Sci. 1996, 51, 1187.

(13) Tao, G.; Kokotovic, P. V. Adaptive Control of Systems with Unknown Output Backlash. IEEE Trans. Automat. Control 1995 40, 326.

(14) Tyreus, B. D.; Luyben, W. L. Tuning of PI Controllers for Integrator/Deadtime Processes. Ind. Eng. Chem. Res. 1992, 31, 2625.

(15) Wallen, A. Valve Diagnostic and Automatic Tuning. Proc. ACC 1997, 2930.

(16) Wang, Q. G.; Hang, C. C.; Zou, B. Low-Order Modeling from Relay Feedback. Ind. Eng. Chem. Res. 1997, 36, 375.

(17) Wu, K. L.; Yu, C. C. Reactor/Separator Process with Recycle 1. Candidate Control Structure for Operability. Comput. Chem. Eng. 1996, 20, 1291.

(18) Yu, C. C. Autotuning of PID Controllers: Relay Feedback Approach; Springer-Verlag: London, 1999.

(19) Ziegler, J. G.; Nichols, N. B. Optimum Settings for Automatic Controllers. Trans. ASME 1942, 12, 759.

Received for review J anuary 3, 2000 Accepted J uly 14, 2000

IE000008H 